\title{
Model estimates of the burden of outpatient visits attributable to influenza in the United States
}

\author{
Gonçalo Matias ${ }^{1 *}$, François Haguinet ${ }^{1}$, Roger L. Lustig² ${ }^{2}$ Laurel Edelman³ ${ }^{3,4}$, Gerardo Chowell ${ }^{5}$ and Robert J. Taylor ${ }^{2}$
}

\begin{abstract}
Background: Although many studies have modelled the national burdens of hospitalizations and deaths due to influenza, few studies have considered the outpatient burden. To fill this gap for the United States (US), we applied traditional statistical modelling approaches to time series derived from large medical claims databases held in the private sector.

Methods: We accessed ICD-9-coded office visit data extracted from Truven Health Analytics' MarketScan Commercial database covering about one third of the US population <65 years during 2001-2009, and Medicare Supplemental data covering about one fifth of US seniors 65+ during 2006-2009. We extracted weekly time series of visits due to respiratory diagnoses, otitis media (OM), and urinary tract infections (UTI), a "negative control". We used multiple linear regression modelling to estimate age-specific influenza-related excess in office visits.

Results: In the $<65$ year age group, in the 8 pre-pandemic seasons studied and for the broadest defined respiratory outcome, the model attributed an average of $14.5 \mathrm{M}$ (Standard deviation [SD] across seasons 3.9 million) office visits to influenza (rate of 5,581/100,000 population). Of these, 80 \% of visits occurred in the 5-17 and 18-49 age group. In school children aged 5-17 year olds and adult 18-64 year age groups the majority of visits were due to influenza B, while A/H3N2 explained most visits in children $<5$ year olds. The model further attributed $\sim 2.2 \mathrm{M} O \mathrm{M}$ visits (SD across seasons 790,000) annually to influenza, of which $86 \%$ of these occurred in children < 18 years; this indicates that $6.4 \%$ of all infants $<2$ years and $4.9 \%$ of all toddlers aged 2-4 years in the US have an influenzaattributable outpatient visit with an OM diagnosis. In seniors 65 years and older, our model attributed $\sim 0.7 \mathrm{M}$ (SD across seasons 351,000 ) respiratory visits to influenza (rate of 1,887/100,000 population). The model identified no significant excess UTI (negative control) visits in most seasons.
\end{abstract}

Conclusions: This is to our knowledge a first study of the outpatient burden of influenza in the US in a large database. The model estimated that $10 \%$ of all children $<18$ years and $4 \%$ of the entire population $<65$ years seek outpatient care for respiratory illness attributable to influenza annually.

Trial registration: ClinicalTrial.gov, NCT02019732.

Keywords: General practice, Influenza, Burden of disease, Mathematical model

\footnotetext{
* Correspondence: goncalo.x.matias@gsk.com

${ }^{1}$ GSK Vaccines, Avenue Fleming 20, Parc de la Noire Epine, Wavre, Belgium

Full list of author information is available at the end of the article
}

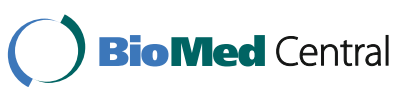

(c) The Author(s). 2016 Open Access This article is distributed under the terms of the Creative Commons Attribution 4.0 International License (http://creativecommons.org/licenses/by/4.0/), which permits unrestricted use, distribution, and reproduction in any medium, provided you give appropriate credit to the original author(s) and the source, provide a link to the Creative Commons license, and indicate if changes were made. The Creative Commons Public Domain Dedication waiver (http://creativecommons.org/publicdomain/zero/1.0/) applies to the data made available in this article, unless otherwise stated. 


\section{Background}

The true burden of influenza is difficult to measure because many infections cause influenza-like-illness and so laboratory testing is needed to confirm influenza, testing of patients is usually at the discretion of the physician so that many influenza infections will not be recorded in clinical databases, and the clinical manifestations of influenza vary in adults and children, which means that influenza may not be suspected $[1,2]$. Because of these difficulties, epidemiologists use indirect statistical approaches to attribute to influenza a portion of seasonal increases in adverse health outcomes that occur during influenza epidemics. These indirect statistical approaches have often been used to estimate the burden of mortality and hospitalisation [3-6]. However, few studies have attempted to quantify the influenza burden in the primary care setting [6-8].

Influenza causes a range of clinical symptoms that are not confined to the respiratory tract, such as gastrointestinal symptoms and febrile convulsions in young children, and sometimes the clinical illness is not particularly severe [9]. For these reasons, influenza is often not properly diagnosed. Otitis media (OM) often prompts young children to consult a physician, and is considered to be a complication of influenza infection $[2,10]$. In a recent evaluation of the influenza primary healthcare burden in the United Kingdom (UK), indirect modelling suggested that $\mathrm{OM}$ attributable to influenza occurred in children at a similar rate to influenza-like-illness, suggesting that rather than being a complication of influenza, OM is part of the clinical symptomatology of influenza in children [8].

The outpatient burden is important because it represents a substantial portion of the economic healthcare burden caused by influenza; that burden also includes absenteeism due to illness among both adults and their children, so that the full burden of paediatric influenza extends beyond children themselves. Estimates of the influenza burden that are limited to respiratory outcomes, such as influenza-like-illness or acute respiratory infection, will not capture the contribution of non-respiratory diseases causes by influenza, such as OM in children. We used retrospective data extracted from MarketScan databases in a time series model to estimate the burden of influenzaattributable physician office visits in the United States (US) by age, influenza strain and season (www.clinicaltrials.gov NCT02019732). We report on a new outcome, 'respiratory disease broadly defined', that combined all respiratory diagnoses with selected presenting symptoms, which was designed to have high sensitivity while maintaining specificity compared to other commonly used outcome definitions such as 'all-cause' or 'respiratory'.

\section{Methods}

Study design

Multiple linear regression models were used to quantify the burden of multiple mild outcomes (i.e., those that result in visits to a physician's office) attributable to influenza in the US, stratifying by age and controlling for the contribution of respiratory syncytial virus (RSV).

We included all physician office visits for a) persons $<65$ years of age with an outcome of interest recorded in the MarketScan Commercial database in the period from July 2001 through March 2009 (eight seasons), and b) persons $65+$ years of age with an outcome of interest that were recorded in the MarketScan Medicare Supplemental database in the period from July 2006 through March 2009 (three seasons). Data from individual subjects were not linked over time.

The study was conducted according to International Society for Pharmacoepidemiology Guidelines for Good Pharmacoepidemiology Practices, local regulations and privacy laws. Consent was not needed as all patients were anonymised and only aggregate data are reported here.

\section{Data sources}

The MarketScan databases used in this study are maintained by Truven Health Analytics (formerly Thomson Medstat), and contain claims data from a variety of health plans [11]. The gender, age, and geographic distribution of the MarketScan population can be weighted to create nationally representative samples of Americans covered by health insurance. At the time of the study the databases covered 110.1 million persons $<65$ years of age and 6.4 million persons aged $65+$ years. It should be noted that the two datasets were different and any comparison of the two sets of estimates should be made cautiously.

Weekly influenza surveillance data were obtained from the Centers for Disease Control and Prevention (CDC) [12]. Influenza virology data were collected for weeks 40 of the first year in a season through week 20 in the second year, by approximately 80 US World Health Organization collaborating laboratories and 60 National Respiratory and Enteric Virus Surveillance Systems (NREVSS) laboratories. Weekly RSV surveillance data were obtained from the NREVSS [13].

\section{Data preparation}

We defined several outcomes of varying sensitivity and specificity using International Classification of Disease (ICD)-9 codes (Table 1). We developed an outcome category 'respiratory disease broadly defined' that included diseases of the respiratory system as well as fever, cough, abnormalities of breathing and unspecified viral infections. A negative control outcome (urinary tract infection) was used to assess the presence of trends not associated with influenza. 
Table 1 Outcomes of interest

\begin{tabular}{ll}
\hline Description & ICD-9-CM \\
\hline $\begin{array}{l}\text { Respiratory Disease Broadly Defined: } \\
\text { Respiratory diseases, fever, cough, }\end{array}$ & $786.7-786.9,079$ \\
abnormalities of breathing, viral & \\
infections NOS & \\
Respiratory Disease & $460-519$ \\
Cardio-respiratory disease & $390-519$ \\
Otitis media & $381-382$ \\
Urinary Tract Infection & 599.0 \\
\hline
\end{tabular}

For each outcome we extracted weekly time series, stratified by age group and region, of the total number of physician office visits recorded during the week divided by the total of covered persons during the same week; records with any mention of defined codes among the recorded diagnoses were included. Weighting factors based on regional populations of age groups were used to remove substantial year-to-year changes in covered populations that occurred each January.

The influenza virology time series were given by the total number of positives by type and subtype, divided by the seasonal total number of influenza tests. The RSV virology time series were given by the number of positives divided by the seasonal total number of RSV tests. The time series for each outcome were stratified by age group. These were merged into the database of weekly outcome time series, by week and year, and employed as explanatory variables.

\section{Statistical methods}

Each age group and region outcome series was modelled by multiple regression. Numbers of influenza-attributable outcome cases were summed across regions, and converted to national rates. Seasonal $95 \%$ confidence intervals (CI) were computed based on the standard error of the multiple regression model parameter for each individual pathogen. We calculated the weekly point estimates as the product of the regression coefficient and the weekly viral circulation, then aggregated the weekly estimates over the entire season. We repeated the procedure using the lower and upper $95 \%$ estimates for the regression parameter to obtain the seasonal upper and lower CIs.

The variability of seasonal all-age estimates was assessed using standard deviations (SD). This SD represents the variability of the attributable burden between seasons and not the uncertainty of the individual seasonal estimates.

The best model fit for both databases adjusted for major holidays using a dummy variable approach. Cyclic terms (sine and cosine with annual period) and lagging of the virology series were considered but not used in the best-fit models. The use of sine and cosine terms to model seasonal variations in disease incidence and disease burden is pervasive in the literature over many decades, made necessary by the absence of data to model seasonal variation in incidence rates. It is intended to capture the effect of "other pathogens" and "other factors" such as weather. The use of sine and cosine terms is intended to capture the effect of "other pathogens" and "other factors" such as weather in seasonal variations in disease incidence and disease burden. In our initial model, cyclic terms captured a high fraction of the attribution rates across defined outcomes. As a result, the attribution rates assigned to other terms in the model (RSV and influenza virology indicators) tended to be much smaller (and often negative) than attribution rates captured by the cyclic terms. On removing cyclic terms from the model, negative attributions were dramatically diminished.

The final model form for the MarketScan Commercial Database was:

$$
\begin{aligned}
Y= & \beta_{1}+\beta_{2} *(R S V)+\beta_{3} *(A / H 1 N 1)+\beta_{4} \\
& *(A / H 3 N 2)+\beta_{5} *(B)+\beta_{6} t+\beta_{7} t^{2}+\beta_{8} t^{3}
\end{aligned}
$$

where $\mathrm{t}$ is the week number, $\mathrm{Y}$ is the incidence of an outcome in each time period t, RSV \& influenza (A/ $\mathrm{H} 1 \mathrm{~N} 1, \mathrm{~A} / \mathrm{H} 3 \mathrm{~N} 2$ and $\mathrm{B}$ ) are the proportions of laboratory isolates during $\mathrm{t}$.

Medicare Supplemental data were limited to three seasons. Collinearity amongst the various virus terms resulted in unstable results and poor fits. We therefore aggregated the influenza terms $(\mathrm{A} / \mathrm{H} 1 \mathrm{~N} 1, \mathrm{~A} / \mathrm{H} 3 \mathrm{~N} 2$ and B) into a single influenza term in the model; we then made seasonal attributions to each type/subtype according to the seasonal proportion of positive samples. The final model form was:

$$
\begin{aligned}
Y= & \beta_{1}+\beta_{2} *(R S V)+\beta_{3} *(\text { Aggregated Influenza }) \\
& +\beta_{4} t+\beta_{5} t^{2}+\beta_{6} t^{3}
\end{aligned}
$$

Statistical analyses were performed using SAS 9.3.

\section{Results \\ Model fit}

The model fit $\left(\mathrm{R}^{2}\right)$ for physician visits for respiratory disease (broadly defined) ranged from 0.54 to 0.79 in the MarketScan Commercial dataset, and from 0.55 to 0.80 in the Medicare Supplemental dataset. The addition of the virology terms to the model increased $R^{2}$ in all strata, by amounts ranging from 0.29 to 0.70 . Figure 1 shows example attributions and model fit to the data.

Between 2001 and 2009, there was an average of 150 million physician visits per season for a respiratory illness (broadly defined) by individuals aged $<65$ year olds in the US. Of these, an estimated 14.5 million visits (9.6\%) (SD across seasons 3.9 million) were attributable to influenza (Table 2); of which $1.7 \%$ were attributed to influenza $\mathrm{A} / \mathrm{H} 1 \mathrm{~N} 1,3.9 \%$ to influenza $\mathrm{A} / \mathrm{H} 3 \mathrm{~N} 2$ and 


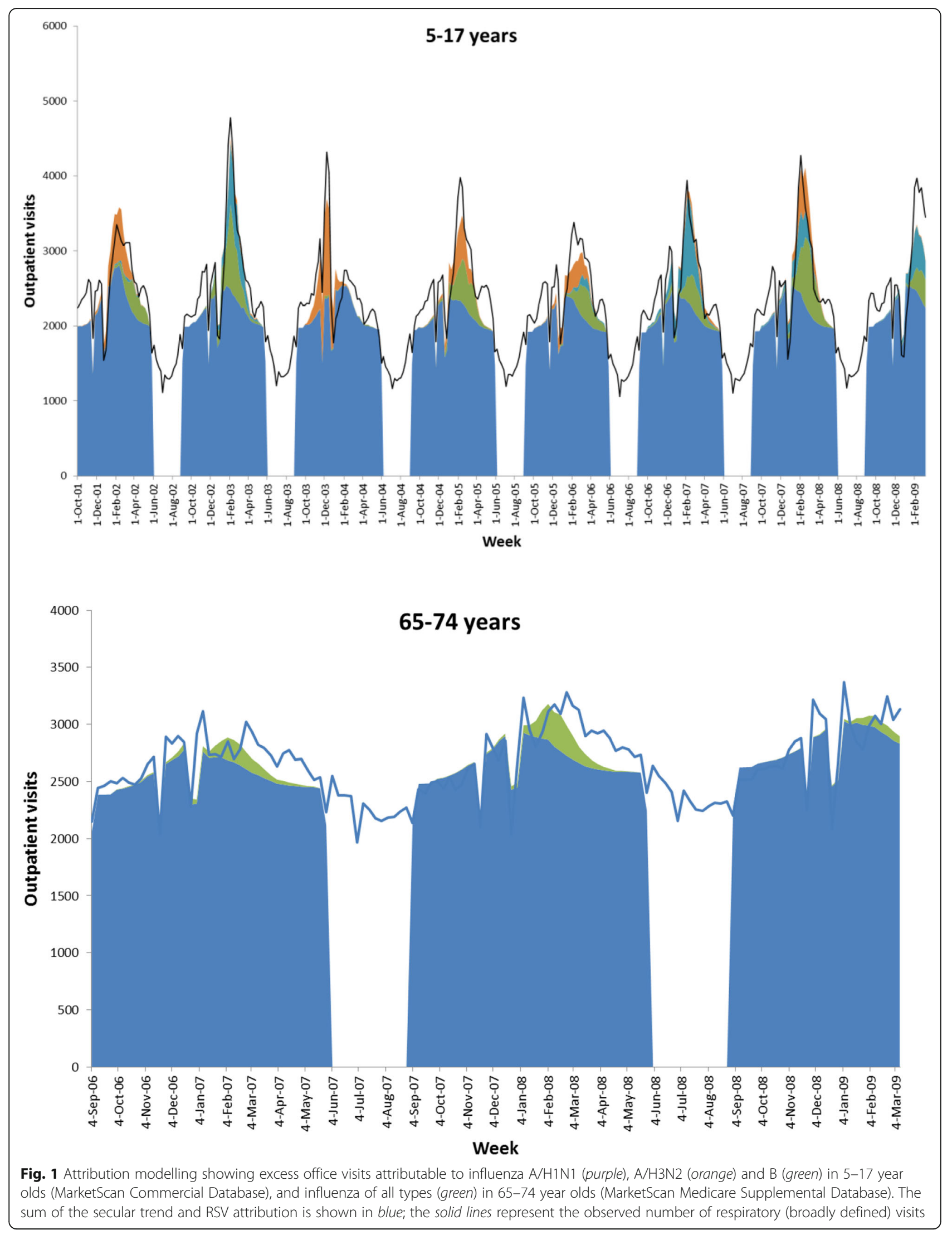


Table 2 Estimated counts of influenza-attributable office visits for respiratory (broadly defined), respiratory and cardiorespiratory causes in the United States, 2001-02 through 2008-09

\begin{tabular}{|c|c|c|c|c|c|c|}
\hline \multirow[b]{2}{*}{ Season } & \multicolumn{2}{|c|}{ Respiratory (broad) } & \multicolumn{2}{|l|}{ Respiratory } & \multicolumn{2}{|c|}{ Cardiorespiratory } \\
\hline & Estimate & $(95 \% \mathrm{Cl})$ & Estimate & $(95 \% \mathrm{Cl})$ & Estimate & $(95 \% \mathrm{Cl})$ \\
\hline \multicolumn{7}{|c|}{ MarketScan Commercial Database, $<65$ year olds } \\
\hline $2001-02$ & $12,365,184$ & $(11,665,801-13,064,541)$ & $10,475,575$ & $(9,816,954-11,134,170)$ & $10,194,445$ & $(9,522,888-10,866,003)$ \\
\hline 2002-03 & $16,803,325$ & $(15,883,426-17,723,224)$ & $14,701,362$ & $(13,836,458-15,566,240)$ & $14,554,184$ & $(13,664,649-15,443,744)$ \\
\hline 2003-04 & $13,618,103$ & $(12,767,860-14,468,321)$ & $11,354,261$ & $(10,556,090-12,152,431)$ & $11,258,742$ & $(10,426,957-12,090,553)$ \\
\hline 2004-05 & $15,814,272$ & $(15,089,234-16,539,284)$ & $13,605,842$ & $(12,927,419-14,284,264)$ & $13,643,186$ & $(12,922,048-14,364,325)$ \\
\hline 2005-06 & $11,795,968$ & $(11,243,720-12,348,242)$ & $10,071,294$ & $(9,555,005-10,587,610)$ & $10,213,174$ & $(9,660,795-10,765,500)$ \\
\hline 2006-07 & $14,628,435$ & $(13,601,384-15,655,487)$ & $12,634,875$ & $(11,674,057-13,595,718)$ & $12,989,309$ & $(11,977,996-14,000,621)$ \\
\hline 2007-08 & $21,896,301$ & $(20,932,203-22,860,399)$ & $18,921,369$ & $(18,020,955-19,821,782)$ & $19,535,453$ & $(18,554,039-20,516,840)$ \\
\hline 2008-09 & $8,683,598$ & $(8,167,552-9,199,670)$ & $7,535,656$ & $(7,053,640-8,017,619)$ & $7,780,771$ & $(7,262,485-8,299,004)$ \\
\hline Average & $14,450,648$ & - & $12,412,529$ & - & $12,521,158$ & - \\
\hline Std dev & $3,931,783$ & - & $3,447,860$ & - & $3,578,048$ & - \\
\hline \multicolumn{7}{|c|}{ MarketScan Medicare Supplemental Database, 65+ year olds } \\
\hline $2006-07$ & 708,335 & $(354,590-1,062,080)$ & 615,166 & $(286,572-943,759)$ & 265,729 & $(0-682,663)$ \\
\hline $2007-08$ & $1,078,071$ & $(535,820-1,620,322)$ & 936,707 & $(432,929-1,440,484)$ & 396,427 & $(0-1,026,793)$ \\
\hline 2008-09 & 376,923 & $(185,672-568,173)$ & 327,184 & $(149,709-504,659)$ & 132,283 & $(0-343,834)$ \\
\hline Average & 721,110 & - & 626,352 & - & 264,813 & - \\
\hline Std dev & 350,749 & - & 304,915 & - & 132,074 & - \\
\hline
\end{tabular}

$<65$ years olds: 2001-02 through 2008-09 seasons, MarketScan Commercial Database

65+ year olds: 2006-09 seasons, MarketScan Medicare Supplemental Database

Std dev $=$ standard deviation, average $=$ mean seasonal estimate

$95 \% \mathrm{Cl}=95 \%$ confidence intervals

$4.1 \%$ to influenza B. Assuming one office visit per individual, the data correspond to an average of 5.6 primary care visits for respiratory disease per 100 persons aged $<65$ years annually.

The seasonal average rate of influenza-attributable office visits was highest among children in age groups $<18$ years (Table 3). Influenza A disease appeared to be less common after age 17 years and decreased further with age. This trend was less marked for influenza B; with high rates of office visits attributable to influenza B respiratory disease persisting until 50-64 years of age.

Among 65+ year olds, in an average season there were $31,644,400$ office visits for a respiratory illness (broadly defined), of which $2.3 \%(n=721,110)$ (SD across seasons $350,749)$ were for respiratory disease attributable to influenza (Table 2). While the estimated rates of influenzaattributable office visits for respiratory disease were lower in the elderly than in children, the number of office visits in $65+$ year olds exceeded those in infants $0-1$ year of age (Table 3). The estimated rate of influenza-attributable office visits for respiratory disease was $28 \%$ higher in $75+$ year olds than in 65-74 year olds (Table 3 ).

There was marked inter-seasonal variability in influenza attributions for respiratory (broadly defined) office visits overall, and in the predominant influenza type (Table 2). The highest estimate of influenza-attributable office visits in both databases was in 2007/08, and the lowest estimate was in 2008/09). In these seasons, influenza-attributable respiratory infection (broadly defined) represented 13 and $6 \%$ of the burden of respiratory illness respectively among 0-64 year olds.

Respiratory illness due to influenza in people $<65$ years was predominantly attributable to influenza A/H3N2 in the 2001/02, 2003/04 and 2005/06 seasons, approximately equally attributable to $\mathrm{A} / \mathrm{H} 3 \mathrm{~N} 2$ and type $\mathrm{B}$ lineages in the 2004/05 season, and predominately to type B in the 2002/ 03, 2007/08 and 2008/09 seasons. Influenza A/H1N1 dominated only in 2006/07, a season in which influenza B also co-circulated (Table 4). The majority of influenza respiratory disease in adults aged 65+ years was attributable to influenza $\mathrm{A}$, with $\mathrm{A} / \mathrm{H} 1 \mathrm{~N} 1$ and $\mathrm{A} / \mathrm{H} 3 \mathrm{~N} 2$ contributing equally (Table 3 ).

The largest numbers of influenza-attributable office visits was among school-age children (5-17 year olds) and young adults (18-49 year olds), each accounting for nearly $40 \%$ (or 5.6 million consultations in an average season, SD across seasons 1.7 million) of the medically attended burden of influenza in individuals $<65$ year olds in the US (Table 3). Overall, 38 and $47 \%$ of all influenza-associated office visits for respiratory disease in these respective age groups were attributable to influenza $\mathrm{B}$. The other influenza subtypes shared a lower but still comparable burden, 
Table 3 Average seasonal model attributions (number and rate per 100,000 population) by influenza sub-type and age

\begin{tabular}{|c|c|c|c|c|c|c|c|c|c|c|c|c|c|c|c|c|}
\hline \multirow[b]{2}{*}{$\begin{array}{l}\text { Age } \\
\text { group } \\
\end{array}$} & \multicolumn{4}{|c|}{ Influenza A/H1N1 } & \multicolumn{4}{|c|}{ Influenza A/H3N2 } & \multicolumn{4}{|c|}{ Influenza B } & \multicolumn{4}{|c|}{ All influenza } \\
\hline & Rate & SD & $\mathrm{N}$ & $\mathrm{SD}$ & Rate & SD & $\mathrm{N}$ & SD & Rate & SD & $\mathrm{N}$ & $\mathrm{SD}$ & Rate & SD & $\mathrm{N}$ & SD \\
\hline \multicolumn{17}{|c|}{ Respiratory broad } \\
\hline $0-1$ & 1148 & 1292 & 92,543 & 104,232 & 4189 & 3220 & 334,583 & 255,510 & 1958 & 1263 & 157,391 & 101,799 & 7295 & 1933 & 584,517 & 155,296 \\
\hline $2-4$ & 2163 & 2353 & 257,345 & 279,828 & 5252 & 4017 & 619,022 & 470,595 & 2256 & 1473 & 267,541 & 173,631 & 9672 & 2312 & $1,143,907$ & 273,448 \\
\hline $5-17$ & 2824 & 3010 & $1,517,946$ & $1,618,530$ & 3573 & 2771 & $1,914,587$ & $1,481,878$ & 3996 & 2592 & $2,145,385$ & $1,391,299$ & 10392 & 3093 & $5,577,918$ & $1,667,267$ \\
\hline $18-49$ & 438 & 468 & 590,623 & 630,727 & 1787 & 1399 & $2,402,020$ & $1,875,906$ & 1979 & 1282 & $2,666,447$ & $1,727,718$ & 4205 & 1274 & $5,659,089$ & $1,720,149$ \\
\hline $50-64$ & 55 & 60 & 28,749 & 31,093 & 1229 & 957 & 608,283 & 458,111 & 1649 & 1072 & 848,186 & 556,510 & 2933 & 1031 & $1,485,217$ & 555,566 \\
\hline $0-64$ & 953 & 1020 & $2,487,205$ & $2,658,483$ & 2285 & 1781 & $5,878,493$ & $4,539,150$ & 2343 & 1519 & $6,084,951$ & $3,940,675$ & 5581 & 1496 & $14,450,648$ & $3,931,783$ \\
\hline $65-74$ & 654 & 334 & 130,668 & 62,250 & 596 & 722 & 119,328 & 145,317 & 424 & 189 & 85,381 & 37,417 & 1674 & 837 & 335,377 & 164,184 \\
\hline $75+$ & 811 & 383 & 147,352 & 68,341 & 757 & 920 & 137,573 & 167,557 & 574 & 269 & 104,445 & 48,993 & 2142 & 1040 & 389,370 & 188,526 \\
\hline $65+$ & 725 & 356 & 276,803 & 129,745 & 669 & 811 & 255,580 & 310,995 & 492 & 226 & 188,727 & 85,855 & 1887 & 929 & 721,110 & 350,749 \\
\hline \multicolumn{17}{|c|}{ Otitis media } \\
\hline $0-1$ & 976 & 1069 & 78,683 & 86,175 & 1594 & 1301 & 127,280 & 103,167 & 3884 & 2515 & 312,139 & 202,623 & 6455 & 2291 & 518,102 & 186,416 \\
\hline $2-4$ & 821 & 859 & 97,574 & 102,047 & 1492 & 1182 & 175,651 & 138,078 & 2627 & 1697 & 311,427 & 200,700 & 4939 & 1613 & 584,652 & 191,428 \\
\hline $5-17$ & 336 & 354 & 180,606 & 190,499 & 389 & 309 & 208,399 & 165,421 & 771 & 497 & 414,081 & 267,052 & 1496 & 547 & 803,086 & 294,139 \\
\hline $18-49$ & 32 & 34 & 42,940 & 45,757 & 48 & 37 & 64,380 & 50,103 & 111 & 72 & 149,756 & 97,400 & 191 & 74 & 257,076 & 100,433 \\
\hline $50-64$ & 10 & 11 & 5377 & 5685 & 18 & 14 & 8859 & 6695 & 55 & 36 & 28,401 & 18,981 & 83 & 37 & 42,637 & 20,350 \\
\hline $0-64$ & 155 & 164 & 405,177 & 428,584 & 227 & 182 & 584,566 & 462,874 & 468 & 303 & $1,215,805$ & 785,121 & 851 & 301 & $2,205,547$ & 787,106 \\
\hline $65-74$ & 6 & 2 & 1267 & 363 & 6 & 6 & 1102 & 1231 & 4 & 2 & 826 & 404 & 16 & 7 & 3195 & 1447 \\
\hline $75+$ & 1 & 0 & 140 & 89 & 1 & 1 & 132 & 197 & 0 & 0 & 87 & 21 & 2 & 1 & 359 & 179 \\
\hline $65+$ & 3 & 1 & 1196 & 520 & 3 & 3 & 1069 & 1336 & 2 & 1 & 730 & 271 & 8 & 4 & 2994 & 1437 \\
\hline
\end{tabular}

$<65$ years olds: 2001-02 through 2008-09 seasons, MarketScan Commercial Database

65+ year olds: 2006-09 seasons, MarketScan Medicare Supplemental Database

$S D$ standard deviation of the variability of the attributable burden between seasons, $N$ number

Table 4 Estimated counts of influenza-attributable office visits for respiratory disease (broad) in the United States by influenza subtype

\begin{tabular}{|c|c|c|c|c|c|c|}
\hline \multirow[b]{2}{*}{ Season } & \multicolumn{2}{|c|}{ Influenza A/H1N1 } & \multicolumn{2}{|c|}{ Influenza A/H3N2 } & \multicolumn{2}{|l|}{ Influenza B } \\
\hline & Estimate & $(95 \% \mathrm{Cl})$ & Estimate & $(95 \% \mathrm{Cl})$ & Estimate & $(95 \% \mathrm{Cl})$ \\
\hline \multicolumn{7}{|c|}{ MarketScan Commercial Database, $<65$ year olds } \\
\hline $2001-02$ & 244,346 & $(206,437-282,230)$ & $9,591,775$ & $(8,949,669-10,233,881)$ & $2,529,062$ & $(2,349,650-2,708,475)$ \\
\hline 2002-03 & $4,927,892$ & $(4,226,578-5,629,206)$ & 956,554 & $(873,630-1,039,452)$ & $10,918,879$ & $(10,010,801-11,826,957)$ \\
\hline 2003-04 & 2253 & $(1715-2791)$ & $13,208,713$ & $(12,356,831-14,060,570)$ & 407,137 & $(377,772-436,527)$ \\
\hline 2004-05 & 26,162 & $(21,539-30,785)$ & $7,662,099$ & $(7,143,927-8,180,245)$ & $8,126,011$ & $(7,568,687-8,683,335)$ \\
\hline 2005-06 & 679,718 & $(551,518-807,891)$ & $6,668,041$ & $(6,246,233-7,089,875)$ & $4,448,210$ & $(4,124,428-4,771,991)$ \\
\hline 2006-07 & $7,070,007$ & $(5,985,195-8,154,818)$ & $1,809,498$ & $(1,686,185-1,932,810)$ & $5,748,931$ & $(5,289,075-6,208,788)$ \\
\hline 2007-08 & $3,334,887$ & $(2,864,430-3,805,317)$ & $6,838,330$ & $(6,349,764-7,326,895)$ & $11,723,085$ & $(10,930,663-12,515,507)$ \\
\hline 2008-09 & $3,612,374$ & $(3,071,846-4,152,875)$ & 292,933 & $(273,464-312,428)$ & $4,778,291$ & $(4,434,527-5,122,082)$ \\
\hline Average & $2,487,205$ & - & $5,878,493$ & - & $6,084,951$ & - \\
\hline SD & $2,658,483$ & - & $4,539,150$ & - & $3,940,675$ & - \\
\hline
\end{tabular}


with 27 and $34 \%$ of the influenza-associated office visits for respiratory disease by children $5-17$ year olds attributable to influenza $\mathrm{A} / \mathrm{H} 1 \mathrm{~N} 1$ and $\mathrm{A} / \mathrm{H} 3 \mathrm{~N} 2$, respectively.

In an average season we estimate that there were 2,205,547 office visits for influenza-attributable otitis media, representing $10 \%$ of all office visits for OM in $<65$ year olds in the US. The highest rates of influenzaattributable OM were in children (0-1 and 2-4 year olds) with $50 \%$ of all office visits for OM occurring in these age groups combined (Table 3). There was more OM attributed to influenza B than A in all age groups (Fig. 2). As expected, the burden of visits for OM was low in adults.

\section{Control outcome}

The burden of medically-attended urinary-tract infections attributed to influenza by the model was negligible.

\section{Discussion}

To the best of our knowledge, our study is among the first to estimate the burden of outpatient visits attributable to influenza in the US. Using a novel outcome (respiratory disease broadly defined), the model attributed seasonal means of 14,450,648 (SD 3,931,783) $(<65$ year

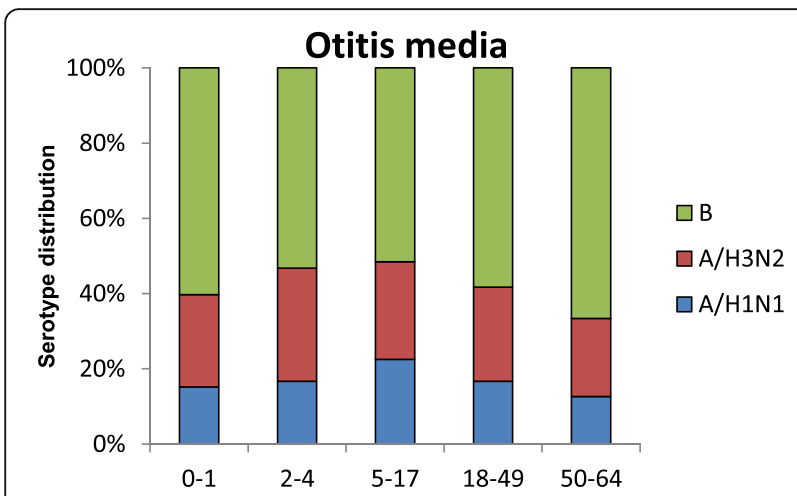

Respiratory disease (broadly defined)

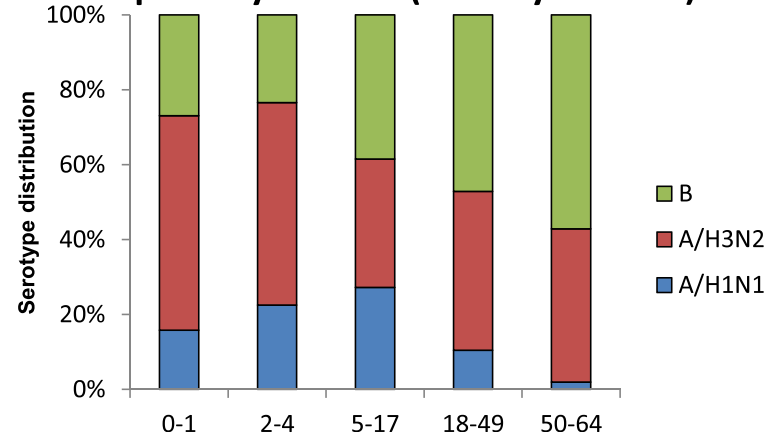

Fig. 2 The percentage of the estimated burdens for respiratory and otitis media outcomes attributed to influenza A and influenza B by age group (mean across seasons, MarketScan Commercial database). Footnote: The total number of office visits for each outcome was: Respiratory disease (broadly defined) $N=115,605,186$, Otitis media $N=17,644,379$ olds) and 721,110 (SD 350,749) (65+ year olds) office visits to influenza for respiratory disease.

Children ( 0 to $<18$ years of age) have the highest rates of medically-attended influenza as determined by the model. This is consistent with previous studies showing that children are responsible for most influenzaattributed doctor visits in the US and UK $[6,8,14]$, but contrasts with results of Molinari et al. [15] who used a probabilistic model and estimated 31.4 million outpatient visits for influenza among all age groups in 2003, with the highest number of consultations in $65+$ year olds. The discrepancy between these results compared to our own and other studies probably reflects the lack of precision associated with the probabilistic approach, which relied on assumptions for influenza consultation rates guided by published clinical trials or epidemiological studies.

While young children and adolescents have the highest rates of office visits for influenza attributable respiratory infections, some other studies indicate that the elderly exhibit the highest influenza-attributable hospitalisations and mortality rates (Table 5).

Olson et al. [16] reported excess visits for "respiratory and fever" syndrome in emergency departments in New York City between 2001 and 2006. The burden of influenza among children $<2$ and $2-4$ years of age estimated in the present study was higher than the range determined by Olson et al. for comparable years (range 6508-9633 visits per 100,000 population versus 540 7710 visits per 100,000 population in $<2$ year olds, and $8226-11,959$ versus $610-4790$ per 100,000 population in 2-4 year olds, respectively), and was higher for other comparable age groups. This difference might be expected if emergency department visits represent only a fraction of office visits. In another study, Fowlkes et al. [14] used 38 outpatient practices to estimate the incidence of medically attended influenza at the community level. Overall, our estimates were in reasonable agreement with those published by Fowlkes et al. However, that study was restricted to a single season (2009/10), in which the influenza $\mathrm{A} / \mathrm{H} 1 \mathrm{~N} 1$ pandemic strain vastly predominated in the US.

Two studies set in the UK assessed the burden of influenza-attributable respiratory illness in primary care. Our estimates are higher than those of Pitman et al. [6] and Fleming et al. [8] for all comparable age groups. The estimates of the burden of medically-attended influenza produced by Pitman were restricted to a single season (2002/03), which was a mixed A/H3N2 and B season. Burden estimates produced using a single season can be unstable and may be affected by a number of factors, including random inter-seasonal variations in the number of cases diagnosed with a respiratory disease as well as changes in the type and severity of the predominant 
Table 5 Seasonal Influenza attributions (rate per 100,000 population) in selected studies conducted in the US and Europe

\begin{tabular}{|c|c|c|c|c|c|}
\hline Country & Study year & Data source & Outcome & $\begin{array}{l}\text { Age } \\
\text { (yrs) }\end{array}$ & $\begin{array}{l}\text { Event rate (average } \\
\text { per season/100,000 } \\
\text { population) }\end{array}$ \\
\hline \multirow[t]{6}{*}{ UK [8] } & \multirow[t]{6}{*}{ 1995-2009 } & \multirow{6}{*}{$\begin{array}{l}\text { Clinical Practice } \\
\text { Research Datalink }\end{array}$} & \multirow{6}{*}{$\begin{array}{l}\text { Respiratory disease (broadly } \\
\text { defined) general practitioner } \\
\text { visits }\end{array}$} & $0-4$ & 2975 \\
\hline & & & & $5-17$ & 2213 \\
\hline & & & & $18-49$ & 1187 \\
\hline & & & & $50-64$ & 1255 \\
\hline & & & & $65+$ & 1216 \\
\hline & & & & All & 1460 \\
\hline \multirow{8}{*}{$\begin{array}{l}\text { European Paediatric Influenza } \\
\text { Analysis project [17] }\end{array}$} & \multirow[t]{2}{*}{ UK, 2002-2008 } & \multirow{2}{*}{$\begin{array}{l}\text { RCGP Weekly Returns } \\
\text { Service }\end{array}$} & \multirow{8}{*}{$\begin{array}{l}\text { Influenza-like-illness outpatient } \\
\text { visits }\end{array}$} & $0-4$ & 384 \\
\hline & & & & $5-17$ & 315 \\
\hline & \multirow[t]{2}{*}{ Italy, 2003-2008 } & \multirow[t]{2}{*}{ surveillance network } & & $0-4$ & 9229 \\
\hline & & & & $5-17$ & 8915 \\
\hline & \multirow[t]{2}{*}{ Netherlands 2002-2008 } & \multirow[t]{2}{*}{ surveillance network } & & $0-4$ & 925 \\
\hline & & & & $5-17$ & 121 \\
\hline & \multirow[t]{2}{*}{ Spain, 2002-2008 } & \multirow{2}{*}{$\begin{array}{l}\text { Spanish Influenza } \\
\text { Sentinel Surveillance } \\
\text { System }\end{array}$} & & $0-4$ & 2,156 \\
\hline & & & & $5-17$ & 2,955 \\
\hline \multirow[t]{7}{*}{ US [16] } & \multirow[t]{7}{*}{$2001-2006$} & \multirow{7}{*}{$\begin{array}{l}\text { Electronic reporting of } \\
\text { emergency department } \\
\text { chief complaint data } \\
\text { (New York city) }\end{array}$} & \multirow{7}{*}{$\begin{array}{l}\text { "fever and respiratory" } \\
\text { syndrome }\end{array}$} & $<2$ & $540-7710$ \\
\hline & & & & $2-4$ & $610-4790$ \\
\hline & & & & $5-12$ & $380-1230$ \\
\hline & & & & $13-17$ & $140-820$ \\
\hline & & & & $18-39$ & $80-440$ \\
\hline & & & & $40-64$ & $60-340$ \\
\hline & & & & $65+$ & $50-570$ \\
\hline \multirow[t]{6}{*}{ US [24] } & \multirow[t]{6}{*}{ 1993-2008 } & \multirow{6}{*}{$\begin{array}{l}\text { The Healthcare Cost and } \\
\text { Utilization Project }\end{array}$} & \multirow[t]{6}{*}{ Influenza-hospitalizations } & $<1$ & $151 / 100,000 p-y$ \\
\hline & & & & $1-4$ & 39/100,000 p-y \\
\hline & & & & $5-49$ & $17 / 100,000$ p-y \\
\hline & & & & $50-64$ & $6 / 100,000$ p-y \\
\hline & & & & $65+$ & 309/100,000 p-y \\
\hline & & & & All & $64 / 100,000$ p-y \\
\hline \multirow[t]{2}{*}{ US [25] } & \multirow[t]{2}{*}{ 1997-2007 } & \multirow{2}{*}{$\begin{array}{l}\text { National Center for } \\
\text { Health Statistics }\end{array}$} & All-cause deaths & All & 11.92 \\
\hline & & & Respiratory deaths & All & 3.58 \\
\hline \multirow[t]{7}{*}{ US [3] } & \multirow[t]{7}{*}{ 1997-2009 } & \multirow{7}{*}{$\begin{array}{l}\text { US National Vital } \\
\text { Statistics System }\end{array}$} & Respiratory disease & $0-4$ & 0.5 \\
\hline & & & (broadly defined) deaths & $5-17$ & 0.2 \\
\hline & & & & $18-49$ & 0.6 \\
\hline & & & & $51-64$ & 3.5 \\
\hline & & & & $65-74$ & 14.1 \\
\hline & & & & $75+$ & 80.1 \\
\hline & & & & All & 6.6 \\
\hline
\end{tabular}

circulating influenza strain. Wide disparity in the attributable influenza burden between European countries was also noted by Paget et al. [17], who reported seasonal averages for influenza-attributable influenza-likeillness of between 0.4 and $18 \%$ in individual countries (Table 5). In view of the dissimilarities between individual countries, which include differences in population, viral circulation patterns, climatic conditions, healthcare systems and patterns of healthcare utilisation (especially costs and incentives for seeking care), close agreement between studies conducted in the UK and the present estimates would not be anticipated. 
The model attributed a large number of visits for $\mathrm{OM}$ to influenza. As expected, the majority of the influenzaattributable OM burden was in younger age groups. We estimated that $10 \%$ of all office visits for otitis media in $<65$ year olds were attributable to influenza, and that $6 \%$ of all $0-1$ year olds attend for an influenzaattributable otitis media office visit in an average season. Among 0-1 year olds, the seasonal rate of office visits for influenza-attributable $\mathrm{OM}$ was close to that of respiratory disease (broadly defined), lending support to the notion that otitis media is part of the primary symptomatology of influenza in this age group, rather than a complication of influenza [8]. Clinical trials have suggested that influenza vaccination reduces OM in children [18-20], although one trial conducted in young children (6-24 months) showed no impact of influenza vaccination on $\mathrm{OM}$ or on healthcare utilization, suggesting a potential age-related impact on efficacy [21].

As is typical of influenza, the influenza-attributable burden of physician office visits was highly strain and age specific, and varied by season. The 2003/04 season was characterised by a severe A/H3N2 epidemic, whereas a negligible burden was observed in the immediately preceding season. The relative impact of influenza A/H1N1 was small in some seasons for most age groups, but A/ H1N1 particularly affected the young (those $<18$ year olds) and the elderly (65+ year olds) in 2006/07. Influenza A/ H3N2 and B shared most of the burden in adults aged 18-64 years. Among older adults (65+), the attributed burden of respiratory disease was highest for influenza A/ H1N1.. Influenza B caused more office visits for respiratory illness than either $\mathrm{A} / \mathrm{H} 1 \mathrm{~N} 1$ or $\mathrm{A} / \mathrm{H} 3 \mathrm{~N} 2$ in individuals between 5 and 64 years of age. Influenza type $\mathrm{B}$ also caused more $\mathrm{OM}$ than $\mathrm{A} / \mathrm{H} 1 \mathrm{~N} 1$ and $\mathrm{A} / \mathrm{H} 3 \mathrm{~N} 2$ combined in all age groups $<65$ years.

Unexpectedly, the estimated burden of influenza B among adult 50-64 year olds was higher than the burden of influenza $\mathrm{A} / \mathrm{H} 1 \mathrm{~N} 1$ and $\mathrm{A} / \mathrm{H} 3 \mathrm{~N} 2$. Although possibly a valid finding, this result is at odds with epidemiological expectations from previous reports which have shown a predominantly higher burden associated with influenza A/ $\mathrm{H} 3 \mathrm{~N} 2$ in adults. It is possible that the proportion of the attributed burden of $\mathrm{A} / \mathrm{H} 3 \mathrm{~N} 2$ in adults was lower than expected due to the higher temporal overlap between $\mathrm{A} /$ $\mathrm{H} 3 \mathrm{~N} 2$ and influenza B virology peaks in some seasons, undermining the model's ability to appropriately allocate burden to influenza $\mathrm{A} / \mathrm{H} 3 \mathrm{~N} 2$ in such cases.

We optimized the ICD9-coded outcome definition for respiratory illness. Our broader-than-usual definition of a respiratory visit, which included all respiratory diagnosis codes plus fever, cough, abnormalities of breathing and unspecified viral infections, was more sensitive than respiratory disease codes alone while retaining good specificity. By contrast, cardio-respiratory visits yielded fewer influenza-associated cases, possibly because this outcome is likely too non-specific, or because individuals with cardiorespiratory illness are more likely to be hospitalized and less likely to receive primary care.

We recognise several potential limitations of this study. The US has no nationwide data available to study the outpatient disease burden. We used a convenience sample (MarketScan databases) which may be subject to unknown biases and which we extrapolated to a national level. We used two different datasets, which means that the two sets of estimates should be compared cautiously. The available time series for the Medicare database was short (three seasons) requiring use of an aggregated influenza term with distribution to each of the influenza types based on the relative proportion of counts for each strain within influenza-positive specimens. This assumed that the temporal pattern of circulation of each influenza type is the same, and these strains are equally likely to cause a case of the disease outcome modelled. Our model also assumed that the collection of viral data and the detection of outcome events was homogeneous from season to season. This means that the proportion of viral circulation captured, and the conditions under which it was captured, remained the same in each season. We excluded cyclic terms from the final model, and in so doing excluded a seasonal baseline designed to control for unspecified seasonal factors associated with increased morbidity. Although similar in shape to the cyclic term, the RSV virology series had a lower amplitude, and for older age groups peaked earlier than the cyclic pattern associated with the respiratory disease outcome series. As a consequence, a larger fraction of the burden that would be otherwise attributed to the cyclic component may have been attributed to influenza. Overall attribution rates in our study were significantly higher across age-groups compared to models that incorporate cyclic terms, in agreement with a prior study that presented results for both model types [6], suggesting that we may have overestimated the influenza burden. In addition to producing larger attribution rates for influenza, the exclusion of the cyclic term increased estimates of the RSV attributable burden. We did not assess autocorrelation, which could influence the quality of the modelling approach. The OM and respiratory illness burdens are not additive, and it is likely that many patients with an OM also had a respiratory diagnosis. Finally, the model predicted increased visits for respiratory disease in autumn in all of the age groups studied. In the absence of virology results for this period, we are unable to identify the cause of these autumnal peaks, although others have identified increases in respiratory virus infections such as rhinovirus and asthma during autumn in the northern hemisphere [22, 23]. Because a direct comparison with equivalent studies is not possible, the generality of the present findings remains to be 
determined. However, the observation that the present estimates were consistent with expected age-and outcomespecific patterns long-established in the literature gives confidence about these results.

\section{Conclusion}

The respiratory burden of medically-attended influenza illness in the US is high, and is strain- and age-specific, with considerable seasonal variation. Unexpectedly, influenza B was attributed to more influenza-related office visits during the study period than either influenza $\mathrm{A} /$ $\mathrm{H} 3 \mathrm{~N} 2$ or $\mathrm{A} / \mathrm{H} 1 \mathrm{~N} 1$. The highest rates of office visits attributable to influenza were among children. The burden of influenza-attributable $\mathrm{OM}$ in young children is similar to that of respiratory disease. This is one of few studies to model statistically the respiratory burden of medicallyattended influenza illness in the US, and the contribution of influenza-attributable otitis media to that burden. Whether it is a primary symptom of influenza in children, or a complication of influenza, OM is theoretically preventable by vaccination. Understanding all influenzarelated outcomes that contribute to the outpatient burden is important in assessing the cost-benefit of influenza vaccination programmes.

\section{Abbreviations}

CDC: Centers for disease control and prevention; ICD: International classification of disease; NREVSS: National respiratory and enteric virus surveillance systems; RSV: Respiratory syncytial virus; UK: United Kingdom; US: United States; UTI: Urinary tract infection

\section{Acknowledgements}

The authors thank the Sage Analytica team for their contribution to the study, in particular Lone Simonsen for her contribution to the study and her critical review of the manuscript, and Cynthia Schuck-Paim for the analysis of data and interpretation. Authors are also grateful to all teams of GSK Vaccines for their contribution to this study and/or publication, especially Robert Gardner for report writing, Vivek Shinde for his study management contribution and Stephanie Wery for the quality check of the data. Finally, the authors thank Joanne Wolter (Independent medical writer, on behalf of GSK Vaccines) for providing writing services, Veronique Delpire and Mandy Payne (Words and Science, on behalf of GSK Vaccines) and Bruno Dumont (Business \& Decision Life Sciences, on behalf of GSK Vaccines) for editorial assistance and manuscript coordination. These data have been presented in part at the 19th WONCA Europe Conference, Lisbon, Portugal, 2-5 July 2014.

\section{Funding}

GlaxoSmithKline Biologicals SA was the funding source and was involved in all stages of the study conduct and analysis. GlaxoSmithKline Biologicals SA also funded all costs associated with the development and the publishing of the present manuscript.

\section{Availability of data and materials}

Health outcome data that support the findings of this study are available from Truven Health Analytics Inc. (http://www.truvenhealth.com/ your_healthcare_focus/pharmaceutical_and_medical_device/ data_databases_and_online_tools.aspx). However, these data were used under license for the current study, and so are not publicly available. Data are however available from the authors upon reasonable request and with permission of Truven Health Analytics Inc.

The results summary for this study (GSK study number 116730, NCT02019732) is currently available on the GSK Clinical Study Register and can be accessed at http://www.gsk-clinicalstudyregister.com/study/117233\#rs.
The anonymized NIS patient-level data were obtained from the Healthcare Cost and Utilization Project (HCUP). Readers can request the data from HCUP (http://www.ahrq.gov/research/data/hcup/).

The influenza data are in the public domain, and can be obtained from the Centers for Disease Control (http://www.cdc.gov/flu/weekly/overview.htm\#Viral). The RSV data were obtained from the National Respiratory and Enteric Virus Surveillance System (NREVSS). Readers can request the data from the "Respiratory/Picornavirus Team" at nrevss@cdc.gov.

\section{Authors' contributions}

All authors participated in the design, implementation and/or analysis, and interpretation of the study, and in the development of this manuscript. All authors had full access to the data and gave final approval before submission. In particular, RT provided study material; GM, FH, GC and RL provided statistical expertise; RT, LE and RL brought administrative, technical or logistic support; LE and RT contributed to centre co-ordination and acquisition of funding. GC was involved in quality check; RT, RL and LE contributed to collection and assembly of data; RT and LE supervised the study group.

\section{Competing interests}

Gonçalo Matias and François Haguinet are employed by the GSK group of companies. Robert Taylor, Roger Lustig, Laurel Edelman and Gerardo Chowell report having received consulting fees from Sage Analytica LLC, which were paid by the GSK group of companies to perform this study. Robert Taylor has an ownership interest in Sage Analytica, a consultancy in epidemiology and bioinformatics. Gerardo Chowell is a member of the BMC Infectious Disease editorial board.

\section{Consent for publication}

Not applicable.

\section{Ethics approval and consent to participate}

Consent was not needed as all patients were anonymised and only aggregate data are reported here. Ethics approval was not sought for this retrospective database study of anonymised data. The data that support the findings of this study were obtained under license from Truven Health Analytics Inc. (http://www.truvenhealth.com/your_healthcare_focus/ pharmaceutical_and_medical_device/data_databases_and_online_tools.aspx)

\section{Author details}

${ }^{1}$ GSK Vaccines, Avenue Fleming 20, Parc de la Noire Epine, Wavre, Belgium. ${ }^{2}$ Sage Analytica, 4915 St. Elmo Ave., Suite 205, Bethesda, MD 20814, USA. ${ }^{3}$ Symphony Health Solutions, Suite 100, 550 Blair Mill Road, Horsham, PA 19044, USA. ${ }^{4}$ Present address: Independent Outcomes and Healthcare Researcher, 1591 White Chimney Road, West Chester, PA 19380, USA. ${ }^{5}$ School of Public Health, Georgia State University, Atlanta, GA, USA

Received: 28 January 2016 Accepted: 18 October 2016

Published online: 07 November 2016

\section{References}

1. Fleming DM, Elliot AJ, Cross KW. Morbidity profiles of patients consulting during influenza and respiratory syncytial virus active periods. Epidemiol Infect. 2007:135(7):1099-108.

2. Fleming DM, Pannell RS, Elliot AJ, Cross KW. Respiratory illness associated with influenza and respiratory syncytial virus infection. Arch Dis Child. 2005; 90(7):741-6

3. Matias G, Taylor R, Haguinet F, Schuck-Paim C, Lustig R, Shinde V. Estimates of mortality attributable to influenza and RSV in the United States during 1997-2009 by influenza type or subtype, age, cause of death, and risk status. Influenza Other Respir Viruses. 2014;8(5):507-15.

4. Thompson WW, Shay DK, Weintraub E, Brammer L, Cox N, Anderson LJ, et al. Mortality associated with influenza and respiratory syncytial virus in the United States. JAMA. 2003;289(2):179-86.

5. Thompson WW, Shay DK, Weintraub E, Brammer L, Bridges CB, Cox NJ, et al. Influenza-associated hospitalizations in the United States. JAMA. 2004; 292(11):1333-40

6. Pitman RJ, Melegaro A, Gelb D, Siddiqui MR, Gay NJ, Edmunds WJ. Assessing the burden of influenza and other respiratory infections in England and Wales. J Infect. 2007:54(6):530-8. 
7. Der Heiden MA, Köpke K, Buda S, Buchholz U, Haas W. Estimates of excess medically attended acute respiratory infections in periods of seasonal and pandemic influenza in Germany from 2001/02 to 2010/11. PLoS One. 2013; 8(7), e64593.

8. Fleming DM, Taylor R, Haguinet F, Schuck-Paim C, Logie J, Webb D, et al. Influenza-attributable burden in United Kingdom primary care. Epidemiology and Infection. 2015 In Press;

9. Nicholson KG, McNally T, Silverman M, Simons P, Zambon MC. Influenzarelated hospitalizations among young children in Leicestershire. Pediatr Infect Dis J. 2003;22(10 Suppl):S228-30.

10. Heikkinen T, Silvennoinen H, Peltola V, Ziegler T, Vainionpaa R, Vuorinen T, et al. Burden of influenza in children in the community. J Infect Dis. 2004; 190(8):1369-73.

11. Truven Health Analytics Inc. website. Your Healthcare focus - Databases and online tools. [Internet]. [cited 2012 Oct 22]. Available from: http://truvenhealth. com/your-healthcare-focus/life-sciences/data_databases_and_online_tools

12. CDC - Seasonal Influenza (Flu) - Flu Activity \& Surveillance [Internet]. [cited 2014 Jun 29]. Available from: http://www.cdc.gov/flu/weekly/fluactivitysurv.htm

13. CDC - National Respiratory and Enteric Virus Surveillance System (NREVSS) NREVSS [Internet]. [cited 2014 Jun 29]. Available from: http://www.cdc.gov/ surveillance/nrevss/

14. Fowlkes A, Dasgupta S, Chao E, Lemmings J, Goodin K, Harris M, et al. Estimating influenza incidence and rates of influenza-like illness in the outpatient setting. Influenza Other Respir Viruses. 2013;7(5):694-700.

15. Molinari N-AM, Ortega-Sanchez IR, Messonnier ML, Thompson WW, Wortley

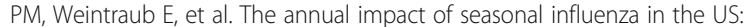
measuring disease burden and costs. Vaccine. 2007;25(27):5086-96.

16. Olson DR, Heffernan RT, Paladini M, Konty K, Weiss D, Mostashari F. Monitoring the impact of influenza by age: emergency department fever and respiratory complaint surveillance in New York City. PLoS Med. 2007;4(8), e247.

17. Paget WJ, Balderston C, Casas I, Donker G, Edelman L, Fleming D, et al. Assessing the burden of paediatric influenza in Europe: the European Paediatric Influenza Analysis (EPIA) project. Eur J Pediatr. 2010;169(8):997-1008.

18. Belshe RB, Mendelman PM, Treanor J, King J, Gruber WC, Piedra P, et al. The efficacy of live attenuated, cold-adapted, trivalent, intranasal influenzavirus vaccine in children. N Engl J Med. 1998;338(20):1405-12.

19. Heikkinen T, Block SL, Toback SL, Wu X, Ambrose CS. Effectiveness of intranasal live attenuated influenza vaccine against all-cause acute otitis media in children. Pediatr Infect Dis J. 2013;32(6):669-74.

20. Clements DA, Langdon L, Bland C, Walter E. Influenza A vaccine decreases the incidence of otitis media in 6- to 30-month-old children in day care. Arch Pediatr Adolesc Med. 1995;149(10):1113-7.

21. Hoberman A, Greenberg DP, Paradise JL, Rockette HE, Lave JR, Kearney DH, et al. Effectiveness of inactivated influenza vaccine in preventing acute otitis media in young children: a randomized controlled trial. JAMA. 2003;290(12): 1608-16.

22. Eggo RM, Scott JG, Galvani AP, Meyers LA. Respiratory virus transmission dynamics determine timing of asthma exacerbation peaks: Evidence from a population-level model. Proc Natl Acad Sci U S A. 2016;113(8):2194-9.

23. Arruda E, Pitkäranta A, Witek TJ, Doyle CA, Hayden FG. Frequency and natural history of rhinovirus infections in adults during autumn. J Clin Microbiol. 1997;35(11):2864-8.

24. Zhou H, Thompson WW, Viboud CG, Ringholz CM, Cheng P-Y, Steiner C, et al. Hospitalizations associated with influenza and respiratory syncytial virus in the United States, 1993-2008. Clin Infect Dis. 2012;54(10):1427-36.

25. Goldstein E, Viboud C, Charu V, Lipsitch M. Improving the estimation of influenza-related mortality over a seasonal baseline. Epidemiology. 2012; 23(6):829-38.

\section{Submit your next manuscript to BioMed Central and we will help you at every step:}

- We accept pre-submission inquiries

- Our selector tool helps you to find the most relevant journal

- We provide round the clock customer support

- Convenient online submission

- Thorough peer review

- Inclusion in PubMed and all major indexing services

- Maximum visibility for your research

Submit your manuscript at www.biomedcentral.com/submit 